\title{
Coordinated Development of Agricultural Water Resources and Socio-Economy in Shanxi Province Considering Uncertainty
}

\author{
Lijuan Huo ${ }^{\mathrm{a}}$, Lirui Ding ${ }^{\mathrm{a}}$, Gaiqiang Yang ${ }^{\mathrm{a}, *}$ \\ ${ }^{\text {a }}$ College of Environment and Safety, Taiyuan University of Science and Technology, \\ Taiyuan, Shanxi 030024, China
}

\begin{abstract}
Conflict between agricultural water resources and socio-economy development is a global problem. Accurate evaluation of coordinated development of agricultural water resources and socio-economy and risk mitigation is necessary for sustainable development. An evaluation method, including selection of criteria, data collection, determination of weight, evaluation of coordinated development, prediction of parameters, and judgment of coordinated development state, has been proposed to study coordinated development degree. To deal with uncertainties, Monte Carlo method and fuzzy set method were used. The method is demonstrated to solve a real-world evaluation problem in Shanxi Province in the middle of China. Results show that coordinated development degrees were $(0.7,0.8)$ for most of the cities of Shanxi in 2015, indicating that coordinate development state was intermediate coordinate. To achieve balanced development, more attention should be put on socio-economic development in Taiyuan and Yanquan, and agricultural water
\end{abstract}


resources utilization in Jinzhong, Yuncheng and Xinzhou. The average coordinated development degree is 0.758 , and coordinate development state was intermediate coordinate from 2006 to 2015. Coordinated development degree has a trend of decreasing markedly, coordinate development state will be barely coordinated, and agricultural water resources utilization lags behind socio-economic development in 2020. The study demonstrates the practicability of the improved method, by evaluating coordinated development degree under uncertainty and forecasting future risks, which will conduce to promote sustainable development of agricultural water resources and socio-economy.

Key words: coordinated development degree; agricultural water resources; socio-economy development; Shanxi Province 


\section{Introduction}

Water resources are vital for the subsistence and development of human society. Water is collected and delivered to farmlands, factories and residential buildings, and then is used to produce goods and provide services. Social development poses huge challenges in improving utilization ratio of water resources and promoting economic growth. Water demand is still increasing for getting more productivity gains, especially in developing countries that already experience serious water shortage . Therefore, it is challenging to effectively and coordinately design water resources utilization and economic development (Li et al., 2019).

Study on coordinated development of water resources and socio-economy has drawn increasing attention worldwide. At the same time, it has also produced many theoretical and practical applications. Current studies primarily focus on investigating the causal relationship (Bao and He, 2015), developing applicable indicators systems (Yang et al., 2018), establishing evaluate model (Song et al., 2018) of economic development level and water use. Methods include system analysis theory (Xiong et al., 2015), state-space method and component analysis (Tang et al., 2016), reduction model (Gu et al., 2017), unified co-evolutionary model (Yao et al., 2018). Evaluation modeling is a powerful tool to quantify interactions or simulate special scenes, hence, it has been applied in previous works in many cases.

Agriculture is the largest consumer of freshwater for producing food which is used to feed a large number of people in China (Li et al., 2019). Agricultural water is 
a critical influence factor of food production. More food production helps increase agricultural economic output; on the other hand, more food production means more agricultural water consumption and less industrial water consumption, and may lead to less industrial economic output. Therefore, relationship between agricultural water consumption and social economic growth is complex. How to make a decision for agricultural water distribution to coordinate economic development is significant, especially for water-deficient regions. For example, Fang et al. (2017) extracted the main driving factors affecting irrigation water-use efficiency change by analyzing statistical data on economic and social development. Yue et al. (Yue et al., 2018) proposed an optimization-based multi-scale calculation method to identify desired water-saving plans that consider the coordinated economy development. There are limited studies focused on the relationship between agricultural water consumption and social economic growth.

Coordinated development of agricultural water resources and social-economy is difficult, due to obvious change of annual available agricultural water volume, complexity of water-economy system and unpredictability of economic conditions (Yang et al., 2017), which lead to uncertainty. Many studies have been reported to deal with uncertainty in evaluation. For example, Wang et al. (Wang et al., 2018) provided an evaluation method for urban water saving. The important degree and the corresponding remark of each evaluation index are considered to be uncertain variables in the method. Lu et al. (Lu et al., 2012) improved a simulation-based 
inexact rough-interval programming approach for agricultural irrigation management. Susnik et al. (Susnik et al., 2013) presented a comparative analysis of system dynamics modeling and object-oriented Bayesian networks which can deal with highly uncertain rainfall contribution. However, only a few studies focused on coordinated development of agricultural water resources and socio-economy with uncertainty. There are many factors affecting coordinated development, which makes the evaluation process considerably more complicated. The value of parameters in models cannot be accurately predicted, especially when evaluating the future risk.

To address uncertainties in the coordinated development of agricultural water resources and social-economy, some uncertain methods, including stochastic mathematical programming, fuzzy mathematical programming and interval mathematical programming, can be adopted. They are able to handle probabilistic, fuzzy uncertainties or interval uncertainties accordingly (Yang et al., 2015). Some existing computer software, such as Lingo and Matlab, are able to solve classical uncertain problems. However, they are inefficient to deal with some nonlinear problems with complex uncertainties. Approaches of particle swarm optimization, genetic algorithm or Monte Carlo method can thus be adopted.

Sustainable agricultural development is not only conducive to sustainable development of Shanxi's economy, but also an important guarantee to achieve the regional grain balance. However, the factors restricting agricultural production are becoming more and more prominent with the population growth and socio-economic 
development. The current situation of agricultural water use in Shanxi is not optimistic. One aspect is that water resources shortage is serious. The per capita water resources is only $247-342 \mathrm{~m}^{3} / \mathrm{a}$, among which about half water supply is for agriculture. Another aspect is the development and utilization of agricultural water resources in Shanxi is unbalanced and inefficient. The effective utilization rate of water in well irrigation area is about $60 \%$, but in canal irrigation area, it is only about 40\%. Agricultural water use plays an important role in Shanxi's economic development. Reasonable development and utilization of regional water resources is significant for maintaining sustainable society and economy development. Therefore, an efficient evaluation method is desired for evaluating coordinated development of agricultural water resources and socio-economy, as well as obtains possible risks caused by uncertainty and complexity in future.

The purpose of this study is to improve a method so as to analyze the probability of coordinated development of agricultural water resources and socio-economy. Accurate evaluation of coordinated development is necessary for sustainable development. From the analysis of evaluation result, degree and direction of maladjustment of regional development can be obtained. To evaluate possible risks, uncertain methods can be used to design and realize forecast coordinated development degree under uncertainty. The improved method is applied to a real case study in Shanxi province, middle of China, a big agricultural province, in order to achieve regional sustainable development. 


\section{Methodology}

Evaluation process for the coordinated development of agricultural water resources and socio-economy includes selection of criteria, data collection, determination of weight, evaluation of coordinated development, prediction of parameters, judgment of coordinated development state and final evaluation. The object of the evaluation objects is to obtain coordinated development degree among different cities, in the status quo and in the future. Detailed information of the framework is depicted in Fig. 1.
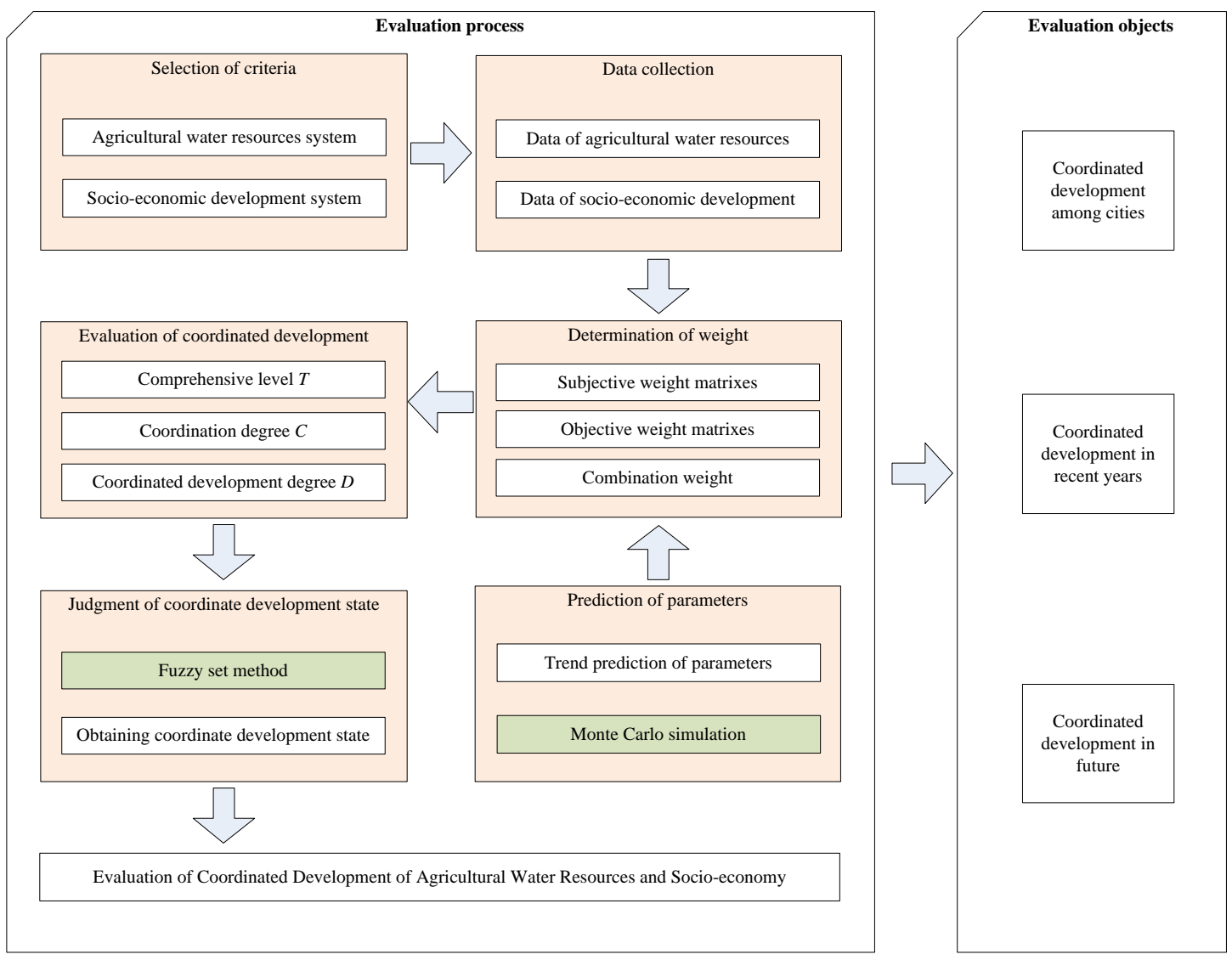

Fig.1 Framework of the study system. 


\subsection{Selection of criteria}

The criteria should be selected based on the pursuit of sustainability in agricultural water resources utilization and developing in socio-economy. According to the concept of regional coordinated development, the criteria of agricultural water resources system should measure the degree of water abundance, water use efficiency and agricultural response conditions, and the criteria of socio-economy development system should measure level of economic development, social development and environmental effect.

Because urban water environment is profoundly and continuously influenced by water usage and effluent water pollution, the ratio of ecological water consumption, wastewater treatment rate and proportion of afforestation area were selected as measurement indicators for urban ecological water supply, environmental pollution and ecological water increase, respectively.

This study selected the following indicators to constitute the evaluation criteria, among which, 9 evaluation indicators are for agricultural water resources and 9 evaluation indicators are for socio-economic development were put forward. Details are shown in Table 1. 
Table 1 Indicator system

\begin{tabular}{|c|c|c|}
\hline target & standard & indicators \\
\hline \multirow{3}{*}{$\begin{array}{l}\text { level of agricultural water } \\
\text { resources (fa) }\end{array}$} & $\begin{array}{l}\text { abundance of agricultural water } \\
\text { resources }\left(\mathrm{fa}_{1}\right)\end{array}$ & $\begin{array}{l}\text { proportion of agricultural water consumption } \\
\left(\mathrm{fa}_{11}\right)(\%) \\
\text { annual precipitation }\left(\mathrm{fa}_{12}\right)(\mathrm{mm}) \\
\text { well irrigation amount per area }\left(\mathrm{fa}_{13}\right)\left(\times 10^{8} \text { ton }\right)\end{array}$ \\
\hline & $\begin{array}{l}\text { utilization state of agricultural } \\
\text { water resources } \quad\left(\mathrm{fa}_{2}\right)\end{array}$ & $\begin{array}{l}\text { water consumption of agricultural ten thousand } \\
\text { RMB output }\left(\mathrm{fa}_{21}\right)\left(\mathrm{m}^{3} / \mathrm{RMB}\right) \\
\text { agricultural intermediate consumption per area } \\
\left(\mathrm{fa}_{22}\right)(\mathrm{RMB} / \mathrm{ha}) \\
\text { efficient utilization coefficient }\left(\mathrm{fa}_{23}\right)\end{array}$ \\
\hline & $\begin{array}{l}\text { agricultural response condition } \\
\left(\mathrm{fa}_{3}\right)\end{array}$ & $\begin{array}{l}\text { applying quantity of chemical fertilizer per area } \\
\left(\mathrm{fa}_{31}\right)(\mathrm{ton} / \mathrm{ha}) \\
\text { total power of agricultural machinery per area } \\
\left(\mathrm{fa}_{32}\right)(\mathrm{kw} / \mathrm{ha}) \\
\text { rural electricity consumption per capita }\left(\mathrm{fa}_{33}\right)\left(\mathrm{x} 10^{4}\right. \\
\mathrm{kwh} / \text { person })\end{array}$ \\
\hline \multirow{3}{*}{$\begin{array}{l}\text { level of socio-economic } \\
\text { development (fe) }\end{array}$} & $\begin{array}{l}\text { level of economic development } \\
\left(\mathrm{fe}_{1}\right)\end{array}$ & $\begin{array}{l}\text { ratio of primary industry to GDP }\left(\mathrm{fe}_{11}\right)(\%) \\
\text { GDP per capita }\left(\mathrm{fe}_{12}\right)\left(\mathrm{x} 10^{3} \mathrm{RMB} / \text { person) }\right. \\
\text { ratio of total retail sales to GDP }\left(\mathrm{fe}_{13}\right)(\%)\end{array}$ \\
\hline & level of social development $\left(\mathrm{fe}_{2}\right)$ & $\begin{array}{l}\text { Natural population growth rate }\left(\mathrm{fe}_{21}\right) \\
\text { Engel's coefficient }\left(\mathrm{fe}_{22}\right)(\%) \\
\text { urbanization rate }\left(\mathrm{fe}_{23}\right)\end{array}$ \\
\hline & $\begin{array}{l}\text { level of ecological environment } \\
\left(\mathrm{fe}_{3}\right)\end{array}$ & $\begin{array}{l}\text { proportion of ecological water use }\left(\mathrm{fe}_{31}\right) \\
\text { rate of sewage treating }\left(\mathrm{fe}_{32}\right)(\%) \\
\text { annual afforestation area ratio }\left(\mathrm{fe}_{33}\right)\end{array}$ \\
\hline
\end{tabular}




\subsection{Determination of weight}

Many methods can be used to determine weights of indicators, including subjective weighting method and objective weighting method (Sahoo et al., 2016). Subjective weighting method is a method of empowerment by experts to compare the importance of each indicator according to their subjective judgment, experience and hobbies, such as Analytic Hierarchy Process (AHP) (Ren et al., 2019). Objective weighting method is based on actual data and objective information reflected by each indicator, such as principal component analysis method and multi-object planning method. In the study, the subjective weighting method and objective weighting method were used simultaneously to determine the importance weight of each indicator. The combined utilization of subjective and objective weighting methods can overcome the shortcomings of single weighting method to some degree, and obtain more scientific and reasonable evaluation results.

a) Determination of subjective weight

Establish subjective evaluation matrices $\mathbf{A}$ for agricultural water resources system and socio-economy development system, respectively. The elements of the matrices are $a_{i j}$, which mean values of scale, and they are determined by the degree of influence between indicator $C_{i}$ and $C_{j}$ which belong to indicator system, as shown in Table 2. 
Table 2 Value of scale

\begin{tabular}{cc}
\hline Scale $a_{i j}$ & Meaning ( influence of indicator $C_{i}$ on indicator $C_{j}$ ) \\
\hline 1 & same \\
3 & slightly stronger \\
5 & stronger \\
7 & obviously stronger \\
9 & absolutely stronger \\
\hline
\end{tabular}

Note: vale of scale $a_{i j}(2,4,6,8)$ represents that influence remains between two adjacent levels.

For consistency test, it is necessary to calculate approximate value of maximum eigenvalue $\lambda$ by formula (1).

$$
\lambda=\frac{\sum_{i=1}^{n} \frac{\left(\mathbf{A} \mathbf{w}^{\prime}\right)_{i}}{w_{i}^{\prime}}}{n}
$$

Where

$$
\begin{aligned}
& \mathbf{w}^{\prime}=\left(w_{1}^{\prime}, w_{2}^{\prime}, \cdots, w_{n}^{\prime}\right)^{T} \\
& w_{i}^{\prime}=\frac{\tilde{w}_{i}}{\sum_{i=1}^{n} \tilde{w}_{i}} \\
& \tilde{w}_{i}=\sum_{j=1}^{n} \frac{a_{i j}}{\sum_{i=1}^{n} a_{i j}}
\end{aligned}
$$

In which $\mathbf{w}^{\prime}$ is the column vector represented subjective weight. $w_{i}^{\prime}$ and $\tilde{w}_{i}$ are temporary variables in the process of calculating $\mathbf{w} . \mathrm{n}$ is the number of indicators.

In order to confirm the consistency of criteria reciprocal matrix, AHP was applied to decompose the decisional process in a hierarchy of criteria, subcriteria, attributes and alternatives.

Consistency Index $(C I)$ is calculated according to formula (5). The more $C I$ is 
close to 0 , the better the consistency is.

$$
C I=\frac{\lambda-n}{n-1}
$$

Consistency Ratio $(C R)$ is an important parameter as Saaty suggested, which is a measure of consistency pairwise comparison matrix. $C R<0.10$ indicated that the new model has satisfactory consistency. The calculation formula is shown as follows.

$$
C R=\frac{C I}{R I}
$$

Where $R I$ is Random Consistency Index which is decided by the order of the judgment matrix $n$ (Debnath et al., 2015).

b) Determination of objective weight

Establish objective evaluation matrices $\mathbf{B}$ for agricultural water resources system and socio-economy development system respectively. The elements of the matrices are $b_{i j}$ which are collected value of indicators, in which $i$ is index of indicators, $j$ is index of regions. It is difficult to analyze these indicators directly because of their inconsistent units. Hence, we used the standardized method for data dimensionless to make the indicators comparably. The transformation methods are described as follows.

$$
b_{i j}^{\prime}= \begin{cases}\left(b_{i j}-b_{\min , j}\right) /\left(b_{\max , j}-b_{\min , j}\right) & \text { for positive indicators } \\ \left(b_{\max , j}-b_{i j}\right) /\left(b_{\max , j}-b_{\min , j}\right) & \text { for negative indicators }\end{cases}
$$

Where $b_{\max , j}$ and $b_{\min , j}$ are maximum value and minimum value of indicator $j$, respectively. $b_{i j}^{\prime}$ are elements of the generated dimensionless matrix.

The column vector represented objective weight is $\mathbf{w}^{\prime \prime}$.

$$
\mathbf{w}^{\prime \prime}=\left(w_{1}^{\prime \prime}, w_{2}^{\prime \prime}, \cdots, w_{n}^{\prime \prime}\right)^{T}
$$


$w_{i}^{\prime \prime}$ is objective weight coefficient and can be calculated as follows.

$w_{i}^{\prime \prime}=\frac{\sigma_{i}}{\sum_{i=1}^{n} \sigma_{i}}$

$\sigma_{i}=\sqrt{\frac{\sum_{j=1}^{n}\left(b^{\prime}{ }_{i j}-\frac{\sum_{j=1}^{n} b^{\prime}{ }_{i j}}{n}\right)^{2}}{n}}$

where $\sigma_{i}$ is mean square error of $b_{i j}^{\prime}$.

c) Determination of combination weight

Combination weight is calculated as follows.

$\mathbf{w}=a \mathbf{w}^{\prime}+b \mathbf{w}^{\prime \prime}$

In which $\mathbf{w}$ is the column vector represented combination weight $\mathbf{w}=\left(w_{1}, w_{2}, \cdots, w_{n}\right)^{T} . a$ and $b$ are weights of $\mathbf{w}^{\prime}$ and $\mathbf{w}^{\prime \prime}$, and $a+b=1$.

2.3 Evaluation of coordinated development

According to formula (7), objective evaluation matrices of agricultural water resources $\mathbf{B}_{\mathbf{a}}$ and objective evaluation matrices of socio-economic development $\mathbf{B}_{e}$ are established. Then according to formula (2), (8), (11), combination weight of agricultural water resources $\mathbf{w}_{\mathbf{a}}$ and combination weight of social-economy development $\mathbf{w}_{\mathbf{e}}$ are calculated. Comprehensive level of agricultural water resources $\mathbf{F}_{\mathrm{a}}$ is calculated as formula (12), and comprehensive level of socio-economic development is calculated as formula (13).

$$
\begin{aligned}
& \mathbf{F}_{\mathrm{a}}=\mathbf{w}_{\mathrm{a}}^{\mathrm{T}} \mathbf{B}_{\mathrm{a}} \\
& \mathbf{F}_{\mathrm{e}}=\mathbf{w}_{\mathrm{e}}^{\mathrm{T}} \mathbf{B}_{\mathrm{e}}
\end{aligned}
$$


a) Determination of comprehensive level

Comprehensive level of agricultural water resources and socio-economic development $\mathbf{T}$ is calculated according to formula (14).

$$
\mathbf{T}=\alpha \mathbf{F}_{a}+\beta \mathbf{F}_{e}
$$

Where $\alpha$ is weight of agricultural water resources, and $\beta$ is weight of socio-economic development, with $\alpha+\beta=1$.

b) Determination of coordination degree

Vector $\mathbf{C}$ expresses the degree of coordination between sustainable utilization of agricultural water resources and socio-economic development. Coordination degree is calculated according to formula (15).

$$
C_{i}=\left(\frac{F_{a i} \times F_{e i}}{T_{i}^{2}}\right)^{k}
$$

Where $C_{i}, F_{a i}, F_{e i}, T_{i}$ are the n-th elements in vector $\mathbf{C}, \mathbf{F}_{a}, \mathbf{F}_{e}, \mathbf{T}$, and $k$ is coordinate coefficient with a general value of $2 \leqslant k \leqslant 5$.

c) Determination of coordinated development degree

Coordinated development degree $\mathbf{D}$ is an improvement of coordination degree C. It reflects the sustainability of agricultural water utilization and socio-economic development models indirectly (Liu et al., 2009). The calculating formula is given in formula (16).

$$
D_{i}=\sqrt{C_{i} T_{i}}
$$

Where $D_{i}$ is the n-th elements in vector $\mathbf{D}$. 


\subsection{Judgment of coordinate development state}

To effectively illustrate the evolution of coordinated development of agricultural water and socio-economic system, fuzzy set method was introduced to establish evaluation criteria for coordinated development (Yuan et al., 2014), as shown in Table 3. The method has been widely applied in the evaluation process as fuzzy membership degree.

Table 3 Evaluation criteria for coordinate development state

\begin{tabular}{ccc}
\hline$D$ & Fuzzy level & Coordinate development state \\
\hline$[0.0,0.1)$ & extreme maladjustment & \\
{$[0.1,0.2)$} & Serious maladjustment & maladjustment \\
{$[0.2,0.3)$} & moderate maladjustment & \\
{$[0.3,0.4)$} & weak maladjustment & Transitional state \\
{$[0.4,0.5)$} & on the verge of disorders & \\
{$[0.5,0.6)$} & barely coordination & coordination \\
{$[0.6,0.7)$} & primary coordination & \\
{$[0.7,0.8)$} & Intermediate coordination & \\
{$[0.8,0.9)$} & Well coordination & \\
\hline$[0.9,1.0]$ & Best coordination & \\
\hline
\end{tabular}

Otherwise, which is easier to maladjustment, agricultural water resources or socio-economic development? The result depends on the value of $F_{a}-F_{e}$. When $F_{a}$ is closer to $F_{e}$, and their distant is less than a small value, they can be approximately considered equal. Let the small value $\Delta=0.1\left|F_{a}-F_{e}\right|$. Judgment of maladjustment in different conditions refers to Table 4. 
Table 4 Object of maladjustment in different conditions

\begin{tabular}{cc}
\hline condition & object of maladjustment \\
\hline$F_{a}-F_{e} \geq \Delta / 2$ & socio-economic development \\
$-\Delta / 2<F_{a}-F_{e}<\Delta / 2$ & Both agricultural water resources and socio-economic development \\
$F_{a}-F_{e} \leq-\Delta / 2$ & agricultural water resources \\
\hline
\end{tabular}

2.5 Forecast and uncertainty analysis

Evaluation of coordinated development is the purpose of the study. However, because most of parameters are uncertainty, it is difficult to obtain accurate forecast and analysis of future coordinated development between agricultural water resources and socio-economic development. To get a more reliable analysis, the uncertainty should be tackled. After analyzing the tendency and range of all parameter in the model, their interval information in the future years can be estimated.

Monte Carlo method is an effective method to handle the parametrical uncertainty analysis. Using this method, some groups of discrete data are generated randomly. Then through the above methodology, coordinated development degrees in particular year in the future can be obtained.

\section{Application}

\subsection{Study area}

The methods were applied to a real case study in the Shanxi province. Shanxi, a central China province, covers 11 county-level cities and 85 counties in 2017 . The distribution of cities is shown in Fig.2. The province lies at the process of economic reform and agricultural development. It has been a key problem to research 
cooperative development of agricultural water resources and social-economy. There are many uncertainties between current and future cooperative level in the province. Such uncertainties dictate the complexity of social-economic development and agricultural water resources utilization.

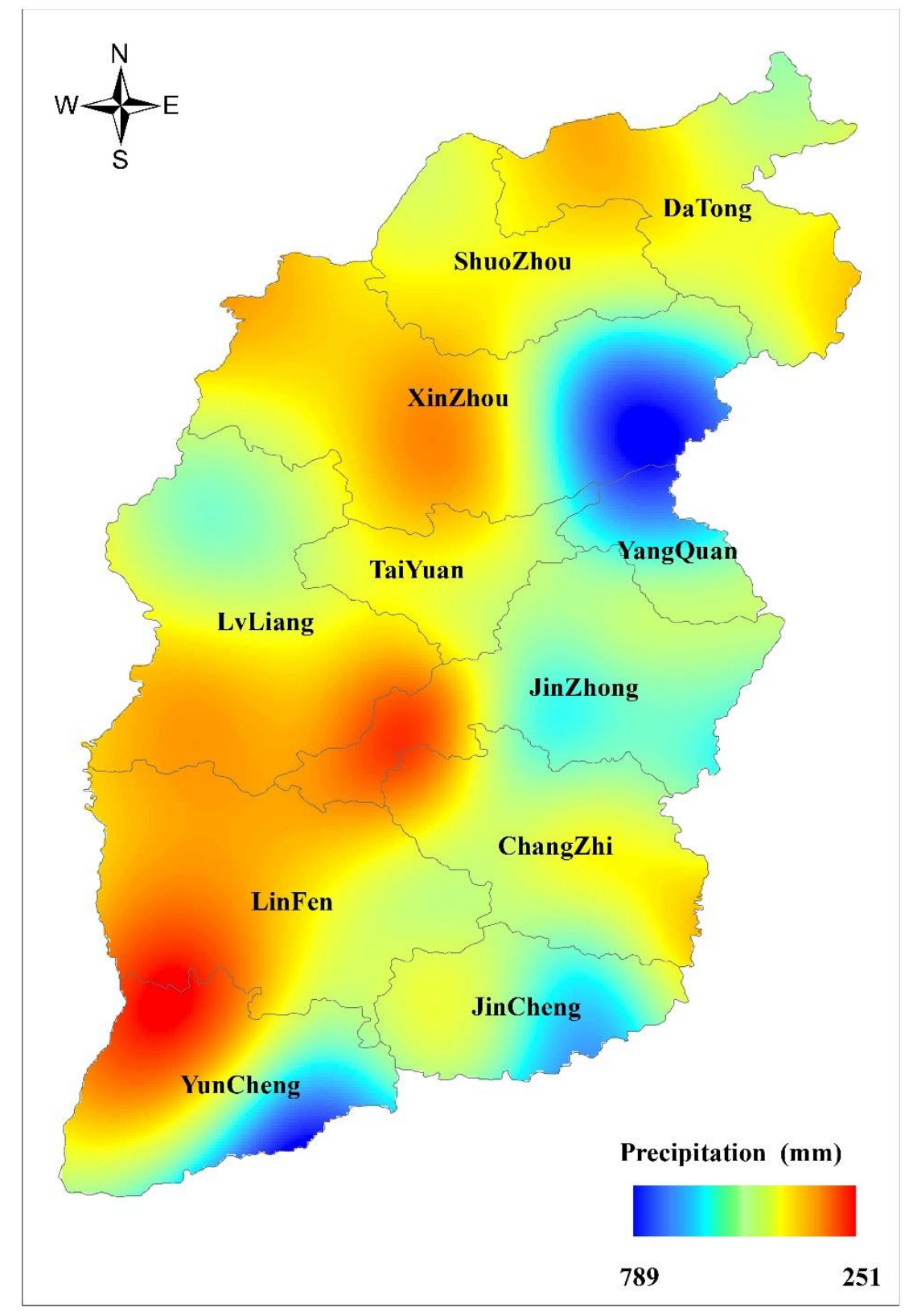

Fig.2 Precipitation distribution in 2015. 
In this study, it is considered that subjective weight and objective weight have same importance, so let $a=b=0.5$ in formula (11). Since rural socioeconomic development level and resources-environment level are equally important in rural development, let $\alpha=\beta=0.5$ in formula (14), and $k=2$ in formula (15) (Liu et al., 2009).

\subsection{Data collection}

Data were collected from local statistics information published by government, such as statistical yearbooks, water resources bulletins, statistics bulletins of national economy and social development of Shanxi province in 2015.

a) Subjective weight matrixes

According to the indicator system (Table 1), subjective weight matrixes of agricultural water resources system and socio-economy development system were estimated, as shown in Table 5 and Table 6.

Table 5 Subjective weight matrixes of agricultural water resources system

\begin{tabular}{cccccccccc}
\hline & $\mathrm{fa}_{11}$ & $\mathrm{fa}_{12}$ & $\mathrm{fa}_{13}$ & $\mathrm{fa}_{21}$ & $\mathrm{fa}_{22}$ & $\mathrm{fa}_{23}$ & $\mathrm{fa}_{31}$ & $\mathrm{fa}_{32}$ & $\mathrm{fa}_{33}$ \\
\hline $\mathrm{fa}_{11}$ & 1.000 & 2.000 & 3.000 & 3.000 & 3.000 & 5.000 & 5.000 & 6.000 & 9.000 \\
$\mathrm{fa}_{12}$ & 0.500 & 1.000 & 3.000 & 3.000 & 3.000 & 5.000 & 5.000 & 7.000 & 8.000 \\
$\mathrm{fa}_{13}$ & 0.333 & 0.333 & 1.000 & 1.000 & 2.000 & 5.000 & 5.000 & 6.000 & 8.000 \\
$\mathrm{fa}_{21}$ & 0.333 & 0.333 & 1.000 & 1.000 & 2.000 & 3.000 & 3.000 & 4.000 & 5.000 \\
$\mathrm{fa}_{22}$ & 0.333 & 0.333 & 0.500 & 0.500 & 1.000 & 3.000 & 3.000 & 4.000 & 5.000 \\
$\mathrm{fa}_{23}$ & 0.200 & 0.200 & 0.200 & 0.333 & 0.333 & 1.000 & 1.000 & 2.000 & 2.000 \\
$\mathrm{fa}_{31}$ & 0.200 & 0.200 & 0.200 & 0.333 & 0.333 & 1.000 & 1.000 & 2.000 & 2.000 \\
$\mathrm{fa}_{32}$ & 0.167 & 0.140 & 0.167 & 0.333 & 0.500 & 0.500 & 0.500 & 1.000 & 2.000 \\
$\mathrm{fa}_{33}$ & 0.111 & 0.125 & 0.125 & 0.200 & 0.200 & 0.500 & 0.500 & 0.500 & 1.000 \\
\hline
\end{tabular}


Table 6 Subjective weight matrixes of socio-economy development system

\begin{tabular}{cccccccccc}
\hline & $\mathrm{fe}_{11}$ & $\mathrm{fe}_{12}$ & $\mathrm{fe}_{13}$ & $\mathrm{fe}_{21}$ & $\mathrm{fe}_{22}$ & $\mathrm{fe}_{23}$ & $\mathrm{fe}_{31}$ & $\mathrm{fe}_{32}$ & $\mathrm{fe}_{33}$ \\
$\mathrm{fe}_{11}$ & 1.000 & 0.330 & 1.000 & 7.000 & 0.330 & 5.000 & 1.000 & 2.000 & 5.000 \\
$\mathrm{fe}_{12}$ & 3.000 & 1.000 & 4.000 & 9.000 & 1.000 & 7.000 & 3.000 & 5.000 & 7.000 \\
$\mathrm{fe}_{13}$ & 1.000 & 0.250 & 1.000 & 5.000 & 0.330 & 3.000 & 0.500 & 2.000 & 3.000 \\
$\mathrm{fe}_{21}$ & 0.143 & 0.111 & 0.200 & 1.000 & 0.125 & 0.330 & 0.143 & 0.250 & 0.500 \\
$\mathrm{fe}_{22}$ & 3.000 & 1.000 & 3.000 & 8.000 & 1.000 & 7.000 & 2.000 & 5.000 & 7.000 \\
$\mathrm{fe}_{23}$ & 0.200 & 0.143 & 0.330 & 3.000 & 0.143 & 1.000 & 0.200 & 0.500 & 2.000 \\
$\mathrm{fe}_{31}$ & 1.000 & 0.330 & 2.000 & 7.000 & 0.500 & 5.000 & 1.000 & 3.000 & 6.000 \\
$\mathrm{fe}_{32}$ & 0.500 & 0.200 & 0.500 & 4.000 & 0.200 & 2.000 & 0.330 & 1.000 & 3.000 \\
$\mathrm{fe}_{33}$ & 0.200 & 0.143 & 0.330 & 2.000 & 0.143 & 0.500 & 0.167 & 0.330 & 1.000 \\
\hline
\end{tabular}

Precipitation distribution of Shanxi in 2015 is shown in Fig.2.

For agricultural water resources system, $C I=0.059, R I=1.45, C R=0.041$. For socio-economy development system, $C I=0.036, R I=1.45, C R=0.025$. Because $\mathrm{CR}<0.1$, satisfactory consistency was obtained, and the subjective weight are available.

b) Objective weight matrixes

Through data survey, objective weight matrixes were obtained as shown in Table 7. 
Table 7 Objective weight matrixes of agricultural water resources system and socio-economy development system

\begin{tabular}{ccccccccccccc}
\hline indicators & Taiyuan & Datong & Yangquan & Changzhi & Jincheng & Shuozhou & Jinzhong & Yuncheng & Xinzhou & Linfen & Lvliang & direction of indicator \\
\hline $\mathrm{fa}_{11}$ & 0.220 & 0.570 & 0.117 & 0.453 & 0.317 & 0.719 & 0.648 & 0.797 & 0.582 & 0.633 & 0.574 \\
$\mathrm{fa}_{12}$ & 455.760 & 435.445 & 585.928 & 459.719 & 531.705 & 439.418 & 489.544 & 458.654 & 469.230 & 390.314 & 433.205 & -1 \\
$\mathrm{fa}_{13}$ & 0.036 & 0.032 & 0.002 & 0.038 & 0.003 & 0.031 & 0.033 & 0.040 & 0.028 & 0.027 & 0.017 \\
$\mathrm{fa}_{21}$ & 0.000 & 0.000 & 0.000 & 0.000 & 0.000 & 0.000 & 0.000 & 0.000 & 0.000 & 0.000 & 0.000 & -1 \\
$\mathrm{fa}_{22}$ & 2.234 & 0.714 & 0.820 & 0.988 & 1.021 & 0.964 & 1.323 & 2.236 & 1.156 & 1.069 & 0.456 & -1 \\
$\mathrm{fa}_{23}$ & 0.550 & 0.570 & 0.490 & 0.500 & 0.490 & 0.490 & 0.470 & 0.510 & 0.511 & 0.510 & 0.550 & -1 \\
$\mathrm{fa}_{31}$ & 0.383 & 0.295 & 0.263 & 0.514 & 0.370 & 0.322 & 0.392 & 0.448 & 0.358 & 0.336 & 0.238 & 1 \\
$\mathrm{fa}_{32}$ & 18.528 & 7.028 & 24.635 & 9.014 & 14.061 & 9.173 & 14.524 & 11.225 & 6.239 & 9.361 & 8.550 \\
$\mathrm{fa}_{33}$ & 0.051 & 0.021 & 0.086 & 0.033 & 0.045 & 0.026 & 0.059 & 0.058 & 0.040 & 0.026 & 0.030 & 1 \\
\hline $\mathrm{fe}_{11}$ & 0.016 & 0.071 & 0.018 & 0.051 & 0.048 & 0.064 & 0.104 & 0.173 & 0.066 & 0.078 & 0.056 \\
$\mathrm{fe}_{12}$ & 57.416 & 23.403 & 39.462 & 35.680 & 44.553 & 48.680 & 30.450 & 22.495 & 21.680 & 26.411 & 23.613 & -1 \\
$\mathrm{fe}_{13}$ & 0.621 & 0.712 & 0.522 & 0.461 & 0.348 & 0.315 & 0.522 & 0.557 & 0.508 & 0.488 & 0.423 \\
$\mathrm{fe}_{21}$ & 4.590 & 4.250 & 4.020 & 4.690 & 2.610 & 4.710 & 4.620 & 4.380 & 4.340 & 4.760 & 5.000 \\
$\mathrm{fe}_{22}$ & 25.900 & 35.100 & 28.000 & 36.500 & 25.000 & 34.900 & 28.900 & 31.900 & 31.670 & 27.300 & 38.700 \\
$\mathrm{fe}_{23}$ & 0.844 & 0.507 & 0.659 & 0.496 & 0.574 & 0.532 & 0.517 & 0.461 & 0.459 & 0.486 & 0.468 & 1 \\
$\mathrm{fe}_{31}$ & 0.033 & 0.028 & 0.119 & 0.039 & 0.019 & 0.013 & 0.024 & 0.003 & 0.032 & 0.041 & 0.057 \\
$\mathrm{fe}_{32}$ & 92.900 & 86.300 & 82.000 & 84.847 & 93.500 & 98.600 & 95.200 & 91.700 & 88.190 & 86.500 & 81.000 \\
$\mathrm{fe}_{33}$ & 0.024 & 0.015 & 0.016 & 0.015 & 0.004 & 0.011 & 0.011 & 0.018 & 0.015 & 0.013 & 0.015 \\
\hline
\end{tabular}

Note: In the column of direction of indicator, 1 means positive indexes and -1 means negative indexes.

After non-dimension process, non-dimensional objective weight matrixes were obtained as shown in Table 8 . 
Table 8 Non-dimensional objective weight matrixes of agricultural water resources system and socio-economy development system

\begin{tabular}{cccccccccccc}
\hline indicators & Taiyuan & Datong & Yangquan & Changzhi & Jincheng & Shuozhou & Jinzhong & Yuncheng & Xinzhou & Linfen & Lvliang \\
\hline $\mathrm{fa}_{11}$ & 0.848 & 0.335 & 1.000 & 0.506 & 0.706 & 0.116 & 0.220 & 0.000 & 0.316 & 0.241 & 0.329 \\
$\mathrm{fa}_{12}$ & 0.665 & 0.769 & 0.000 & 0.645 & 0.277 & 0.749 & 0.493 & 0.651 & 0.597 & 1.000 & 0.781 \\
$\mathrm{fa}_{13}$ & 0.108 & 0.228 & 1.000 & 0.051 & 0.979 & 0.244 & 0.189 & 0.000 & 0.327 & 0.360 & 0.603 \\
$\mathrm{fa}_{21}$ & 0.731 & 0.000 & 1.000 & 0.753 & 0.850 & 0.205 & 0.655 & 0.638 & 0.547 & 0.695 & 0.164 \\
$\mathrm{fa}_{22}$ & 0.001 & 0.855 & 0.796 & 0.702 & 0.683 & 0.715 & 0.513 & 0.000 & 0.607 & 0.656 & 1.000 \\
$\mathrm{fa}_{23}$ & 0.200 & 0.000 & 0.800 & 0.700 & 0.800 & 0.800 & 1.000 & 0.600 & 0.590 & 0.600 & 0.200 \\
$\mathrm{fa}_{31}$ & 0.474 & 0.796 & 0.910 & 0.000 & 0.522 & 0.696 & 0.444 & 0.238 & 0.566 & 0.644 & 1.000 \\
$\mathrm{fa}_{32}$ & 0.332 & 0.957 & 0.000 & 0.849 & 0.575 & 0.841 & 0.550 & 0.729 & 1.000 & 0.830 & 0.874 \\
$\mathrm{fa}_{33}$ & 0.533 & 1.000 & 0.000 & 0.813 & 0.623 & 0.919 & 0.407 & 0.422 & 0.706 & 0.920 & 0.853 \\
\hline $\mathrm{fe}_{11}$ & 1.000 & 0.650 & 0.984 & 0.775 & 0.797 & 0.692 & 0.438 & 0.000 & 0.679 & 0.606 & 0.741 \\
$\mathrm{fe}_{12}$ & 0.000 & 0.952 & 0.502 & 0.608 & 0.360 & 0.244 & 0.755 & 0.977 & 1.000 & 0.868 & 0.946 \\
$\mathrm{fe}_{13}$ & 0.228 & 0.000 & 0.477 & 0.632 & 0.917 & 1.000 & 0.480 & 0.390 & 0.513 & 0.564 & 0.728 \\
$\mathrm{fe}_{21}$ & 0.172 & 0.314 & 0.410 & 0.130 & 1.000 & 0.121 & 0.159 & 0.259 & 0.276 & 0.100 & 0.000 \\
$\mathrm{fe}_{22}$ & 0.934 & 0.263 & 0.781 & 0.161 & 1.000 & 0.277 & 0.715 & 0.496 & 0.513 & 0.832 & 0.000 \\
$\mathrm{fe}_{23}$ & 0.000 & 0.876 & 0.482 & 0.905 & 0.701 & 0.812 & 0.849 & 0.995 & 1.000 & 0.930 & 0.978 \\
$\mathrm{fe}_{31}$ & 0.737 & 0.786 & 0.000 & 0.691 & 0.862 & 0.911 & 0.818 & 1.000 & 0.749 & 0.673 & 0.534 \\
$\mathrm{fe}_{32}$ & 0.324 & 0.699 & 0.943 & 0.781 & 0.290 & 0.000 & 0.193 & 0.392 & 0.591 & 0.688 & 1.000 \\
$\mathrm{fe}_{33}$ & 0.000 & 0.454 & 0.389 & 0.442 & 1.000 & 0.666 & 0.669 & 0.322 & 0.467 & 0.544 & 0.435 \\
\hline
\end{tabular}

c) Statistical data from 2005 to 2015

In order to obtain accurate forecast and analysis of future coordinated development between agricultural water resources and 
socio-economic development, statistical data of Shanxi province from 2005 to 2015 were collected as shown in Table 9.

Table 9 Statistical data of agricultural water resources system and socio-economy development system from 2005 to 2015

\begin{tabular}{|c|c|c|c|c|c|c|c|c|c|c|c|}
\hline indicators & 2005 & 2006 & 2007 & 2008 & 2009 & 2010 & 2011 & 2012 & 2013 & 2014 & 2015 \\
\hline $\mathrm{fa}_{11}$ & 0.556 & 0.551 & 0.561 & 0.557 & 0.568 & 0.549 & 0.514 & 0.544 & 0.544 & 0.547 & 0.582 \\
\hline $\mathrm{fa}_{12}$ & 463.000 & 477.800 & 556.300 & 466.400 & 498.700 & 520.000 & 602.110 & 510.100 & 588.300 & 520.900 & 480.600 \\
\hline $\mathrm{fa}_{13}$ & 0.027 & 0.027 & 0.026 & 0.025 & 0.027 & 0.024 & 0.024 & 0.026 & 0.027 & 0.027 & 0.028 \\
\hline $\mathrm{fa}_{21}$ & 0.000 & 0.000 & 0.000 & 0.000 & 0.000 & 0.000 & 0.000 & 0.000 & 0.000 & 0.000 & 0.000 \\
\hline $\mathrm{fa}_{22}$ & 0.386 & 0.412 & 0.471 & 0.531 & 0.572 & 0.690 & 0.844 & 1.004 & 1.097 & 1.211 & 1.156 \\
\hline $\mathrm{fa}_{23}$ & 0.470 & 0.476 & 0.482 & 0.488 & 0.494 & 0.500 & 0.506 & 0.512 & 0.518 & 0.524 & 0.530 \\
\hline $\mathrm{fa}_{31}$ & 0.306 & 0.321 & 0.322 & 0.325 & 0.314 & 0.327 & 0.339 & 0.351 & 0.357 & 0.358 & 0.358 \\
\hline $\mathrm{fa}_{32}$ & 7.308 & 7.718 & 7.793 & 7.883 & 7.999 & 8.325 & 8.653 & 9.057 & 9.390 & 9.829 & 10.120 \\
\hline $\mathrm{fa}_{33}$ & 0.034 & 0.036 & 0.040 & 0.042 & 0.044 & 0.044 & 0.048 & 0.054 & 0.058 & 0.058 & 0.058 \\
\hline $\mathrm{fe}_{11}$ & 0.056 & 0.078 & 0.066 & 0.173 & 0.104 & 0.064 & 0.048 & 0.051 & 0.018 & 0.071 & 0.061 \\
\hline $\mathrm{fe}_{12}$ & 12.815 & 14.698 & 18.056 & 21.776 & 21.464 & 25.709 & 31.209 & 33.584 & 34.892 & 34.983 & 34.842 \\
\hline $\mathrm{fe}_{13}$ & 0.322 & 0.320 & 0.314 & 0.321 & 0.391 & 0.350 & 0.337 & 0.361 & 0.406 & 0.448 & 0.473 \\
\hline $\mathrm{fe}_{21}$ & 6.020 & 5.750 & 5.330 & 5.310 & 4.890 & 5.296 & 4.860 & 4.870 & 5.240 & 4.990 & 4.420 \\
\hline $\mathrm{fe}_{22}$ & 44.200 & 38.500 & 38.500 & 39.000 & 37.100 & 37.500 & 37.700 & 33.400 & 33.000 & 29.400 & 29.000 \\
\hline $\mathrm{fe}_{23}$ & 0.580 & 0.570 & 0.560 & 0.549 & 0.540 & 0.519 & 0.503 & 0.487 & 0.474 & 0.462 & 0.459 \\
\hline $\mathrm{fe}_{31}$ & 0.020 & 0.020 & 0.013 & 0.024 & 0.027 & 0.028 & 0.031 & 0.031 & 0.047 & 0.048 & 0.032 \\
\hline $\mathrm{fe}_{32}$ & 56.230 & 60.220 & 63.320 & 71.400 & 75.200 & 84.900 & 86.500 & 88.000 & 88.400 & 88.400 & 89.200 \\
\hline $\mathrm{fe}_{33}$ & 0.009 & 0.018 & 0.019 & 0.019 & 0.023 & 0.019 & 0.019 & 0.020 & 0.019 & 0.020 & 0.018 \\
\hline
\end{tabular}




\section{Result and analysis}

4.1 Analysis of coordinated development among cities

Based on the methodology, coordinated development results among cities were obtained. Some key results were shown in Table 10. Fig.3 compares the comprehensive levels of agricultural water resources and socio-economic development. It can be seen from the figure that comprehensive level of agricultural water resources is higher than comprehensive level of socio-economic development in Taiyuan, Datong, Yangquan, Changzhi, Shuozhou and Lvling. The big gaps were existed in Yanquan $\left(F_{a}-F_{e}=0.674-0.523\right)$ and Yuncheng $\left(F_{a}-F_{e}=0.337-0.573\right)$.

Table 10 Evaluation results of cities in 2015 .

\begin{tabular}{|c|c|c|c|c|c|c|c|c|c|c|c|}
\hline & Taiyuan & Datong & Yangquan & Changzhi & Jincheng & Shuozhou & Jinzhong & Yuncheng & Xinzhou & Linfen & Lvliang \\
\hline$F_{a}$ & 0.500 & 0.576 & 0.674 & 0.558 & 0.688 & 0.568 & 0.484 & 0.350 & 0.570 & 0.638 & 0.665 \\
\hline$F_{e}$ & 0.439 & 0.557 & 0.523 & 0.549 & 0.713 & 0.540 & 0.600 & 0.573 & 0.652 & 0.656 & 0.575 \\
\hline$T$ & 0.469 & 0.567 & 0.598 & 0.554 & 0.701 & 0.554 & 0.542 & 0.461 & 0.611 & 0.647 & 0.620 \\
\hline$C$ & 0.992 & 0.999 & 0.968 & 1.000 & 0.999 & 0.999 & 0.977 & 0.887 & 0.991 & 1.000 & 0.989 \\
\hline$D$ & 0.682 & 0.752 & 0.761 & 0.744 & 0.837 & 0.744 & 0.728 & 0.640 & 0.778 & 0.804 & 0.783 \\
\hline coordinate development state & $\mathrm{P}$ & I & I & I & W & I & I & $\mathrm{P}$ & I & W & I \\
\hline object of maladjustment & $\mathrm{E}$ & $\mathrm{B}$ & $\mathrm{E}$ & $\mathrm{B}$ & $\mathrm{B}$ & B & A & A & A & $\mathrm{B}$ & $\mathrm{E}$ \\
\hline
\end{tabular}

Note: P--Primary coordination; I--Intermediate coordination; W--Well coordination; A--Agricultural water resources; B-Both agricultural water resources and socio-economic development; E--Socio-economic development. 


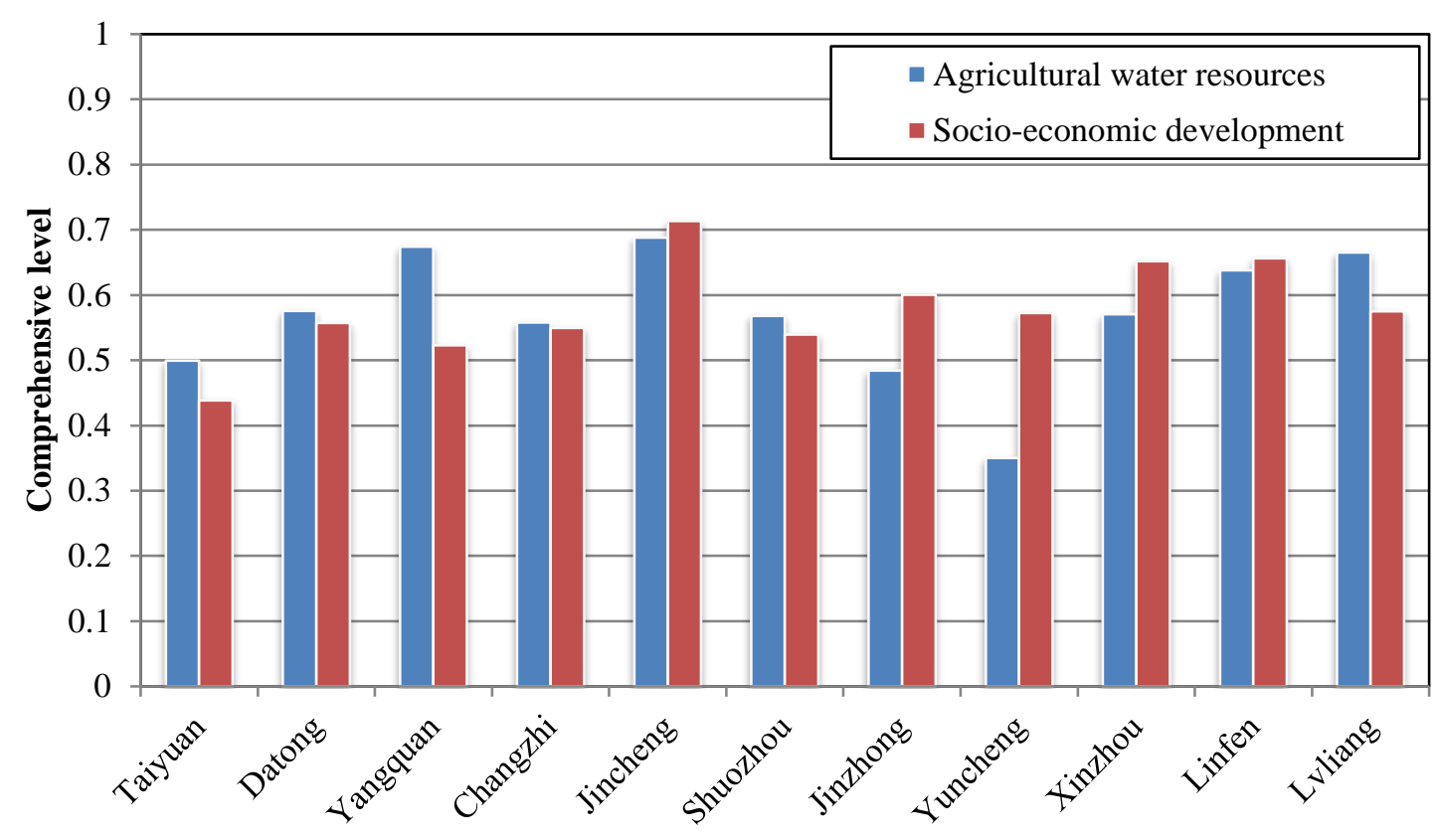

Fig.3 Comprehensive levels of city in 2015.

Efficient utilization coefficient of Taiyuan, Shuozhou, Datong and Lvliang was

high, and precipitation in Yangquan was abundant. Therefore, it was easier to satisfy demand of agricultural water, in turn appears as $\mathrm{F}_{\mathrm{a}}>\mathrm{F}_{\mathrm{e}}$. Meanwhile, the ratio of primary industry to GDP was high in Jinzhong and Yuncheng, accordingly, their economic development is better than utilization of agricultural water.

Coordinated development degrees of different cities in 2015 are shown in Fig.4. Coordinated development degrees are $(0.7,0.8)$ for most of the cities. Jincheng has biggest coordinated development degree (0.837), and Yuncheng has smallest one (0.640). Coordinated development of agricultural water resources and socio-economy in Jincheng was best in cities of Shanxi, for another reason was that its comprehensive 
levels are also highest in all cities $\left(\mathrm{F}_{\mathrm{a}}=0.688, \mathrm{~F}_{\mathrm{e}}=0.713\right)$. Situation of agricultural water resources in Yuncheng was tougher owing to its biggest gaps of comprehensive levels $\left(F_{a}-F_{e}=-0.236\right)$.

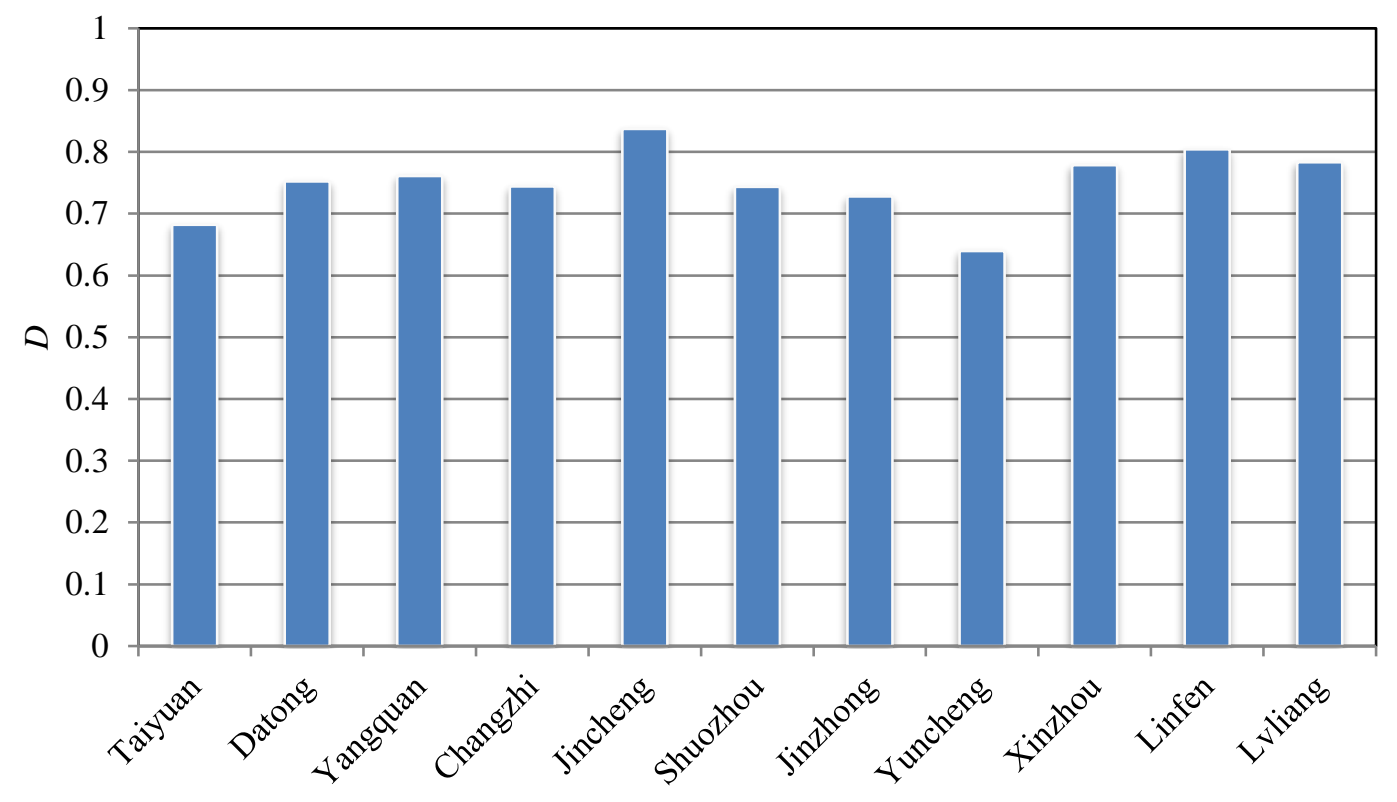

Fig.4 Coordinated development degrees of city in 2015.

In view of the overall situation, coordinate development state of Shanxi was intermediate coordination in 2015. Coordinate development state of Taiyuan and Yuncheng was primary coordination, and coordinate development state of Jincheng and Linfen was well coordination. Taiyuan and Yangquan had slow socio-economic development. Jinzhong, Yuncheng and Xinzhou had low agricultural water resources utilization.

To achieve balanced development, it is critical to focus on socio-economic development of Taiyuan and Yanquan. In addition, agricultural water resources utilization of Jinzhong, Yuncheng and Xinzhou is also important to maintain the 
momentum of sustained development, especial in Yuncheng.

4.2 Analysis of coordinated development from 2005 to 2015

Evaluation results of Shanxi from 2005 to 2015 were shown in Table 11. Fig.5 compares the comprehensive levels of agricultural water resources and socio-economic development from 2005 to 2015. The comprehensive levels of agricultural water resources were lower than the comprehensive levels of socio-economic development except in 2008. It can be seen from the figure that the big gaps are existed in $2007(\mathrm{Fa}-\mathrm{Fe}=-0.150)$. 
Table 11 Evaluation results of Shanxi from 2005 to 2015.

\begin{tabular}{ccccccccccccc}
\hline & 2005 & 2006 & 2007 & 2008 & 2009 & 2010 & 2011 & 2012 & 2013 & 2014 & 2015 \\
\hline$F_{a}$ & 0.640 & 0.617 & 0.551 & 0.610 & 0.606 & 0.589 & 0.511 & 0.550 & 0.468 & 0.511 & 0.526 \\
$F_{e}$ & 0.681 & 0.682 & 0.685 & 0.564 & 0.596 & 0.596 & 0.586 & 0.605 & 0.591 & 0.582 & 0.617 \\
$T$ & 0.661 & 0.649 & 0.618 & 0.587 & 0.601 & 0.592 & 0.549 & 0.577 & 0.529 & 0.546 & 0.572 \\
$C$ & 0.998 & 0.995 & 0.976 & 0.997 & 1.000 & 1.000 & 0.991 & 0.995 & 0.974 & 0.991 & 0.988 \\
$D$ & 0.812 & 0.804 & 0.777 & 0.765 & 0.775 & 0.770 & 0.737 & 0.758 & 0.718 & 0.736 & 0.751 \\
coordinate development state & $\mathrm{W}$ & $\mathrm{W}$ & $\mathrm{I}$ & $\mathrm{I}$ & $\mathrm{I}$ & $\mathrm{I}$ & $\mathrm{I}$ & $\mathrm{I}$ & $\mathrm{I}$ & $\mathrm{I}$ & $\mathrm{I}$ \\
object of maladjustment & $\mathrm{B}$ & $\mathrm{A}$ & $\mathrm{A}$ & $\mathrm{B}$ & $\mathrm{B}$ & $\mathrm{B}$ & $\mathrm{A}$ & $\mathrm{B}$ & $\mathrm{A}$ & $\mathrm{A}$ & $\mathrm{A}$ \\
\hline
\end{tabular}

Note: I--Intermediate coordination; W--Well coordination; A--Agricultural water resources; B-Both agricultural water resources and socio-economic development. 


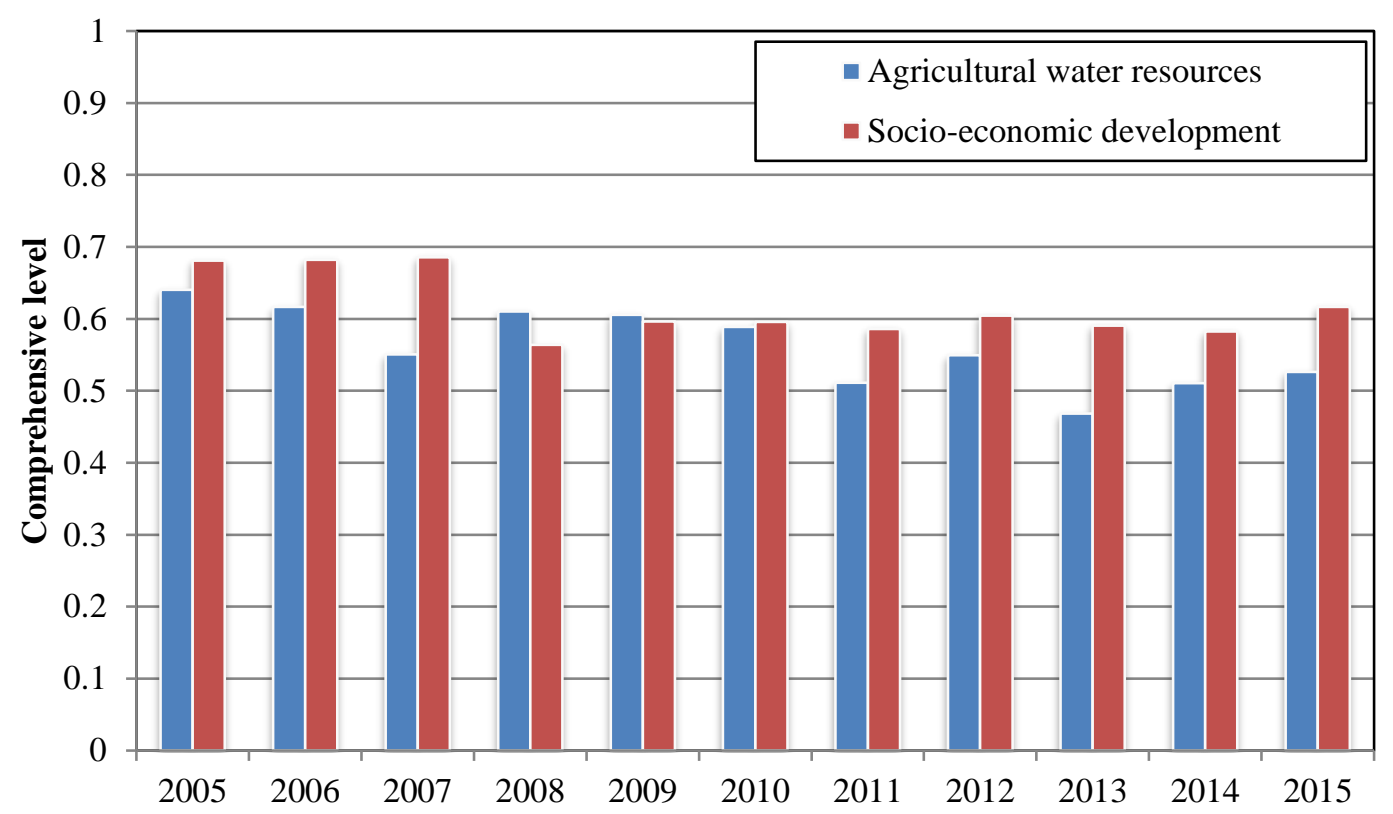

Fig.5 Comprehensive levels of Shanxi from 2005 to 2015.

Fig. 6 shows the year-dependent change of coordinated development degrees of

Shanxi. The average coordinated development degree was 0.758 . It appeared slowly decrease tendency with time prolonged from 2005 to 2015. Coordinate development state of 2005 was well coordinate, while coordinate development states of other years were intermediate coordinate. According to the present trend, maladjustment might be happen. 


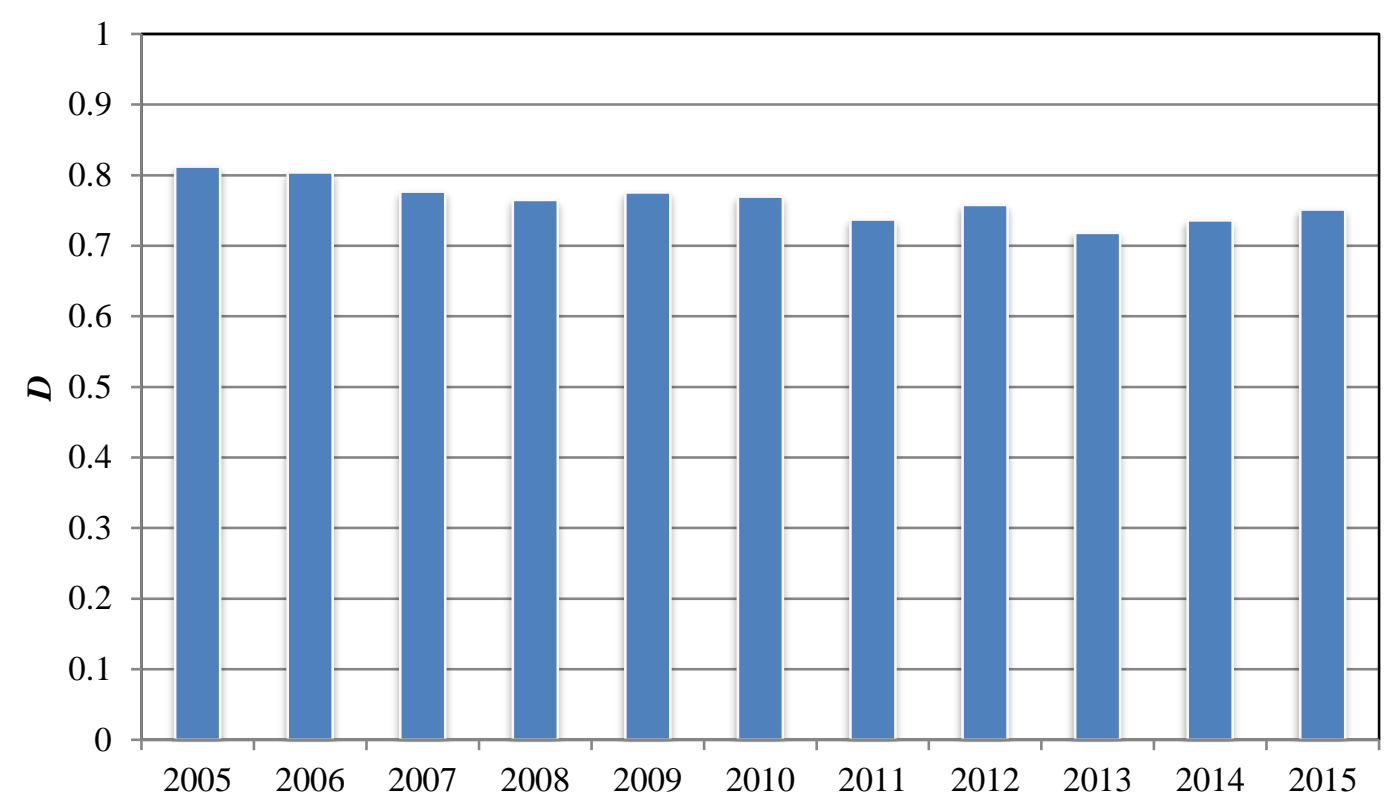

Fig.6 Coordinated development degrees of Shanxi from 2005 to 2015.

4.3 Analysis of coordinated development in future

In order to evaluate the possible risks in future, the study analyzed various data uncertainties of the evaluation system. Interval ranges of indicators are listed in Table 12.

Table 12 Interval number of agricultural water resources system and socio-economy development system in 2020 and 2025

\begin{tabular}{ccc}
\hline indicators & 2020 & 2025 \\
\hline $\mathrm{fa}_{11}$ & {$[0.513,0.581]$} & {$[0.512,0.581]$} \\
$\mathrm{fa}_{12}$ & {$[463.000,602.110]$} & {$[463.000,602.110]$} \\
$\mathrm{fa}_{13}$ & {$[0.025,0.028]$} & {$[0.026,0.029]$} \\
$\mathrm{fa}_{21}$ & {$[0.000,0.000]$} & {$[0.000,0.000]$} \\
$\mathrm{fa}_{22}$ & {$[1.586,1.769]$} & {$[2.047,2.230]$} \\
$\mathrm{fa}_{23}$ & {$[0.560,0.560]$} & {$[0.590,0.590]$} \\
$\mathrm{fa}_{31}$ & {$[0.373,0.396]$} & {$[0.400,0.423]$} \\
$\mathrm{fa}_{32}$ & {$[11.028,11.574]$} & {$[12.405,12.951]$} \\
$\mathrm{fa}_{33}$ & {$[0.069,0.076]$} & {$[0.082,0.089]$} \\
$\mathrm{fe}_{11}$ & {$[0.014,0.167]$} & {$[0.012,0.164]$} \\
$\mathrm{fe}_{12}$ & {$[47.348,53.720]$} & {$[59.854,66.226]$} \\
$\mathrm{fe}_{13}$ & {$[0.465,0.548]$} & {$[3.113,3.907]$} \\
$\mathrm{fe}_{21}$ & {$[3.668,4.462]$} & {$[14.405,19.945]$} \\
$\mathrm{fe}_{22}$ & {$[20.745,26.286]$} &
\end{tabular}




\begin{tabular}{ccc}
$\mathrm{fe}_{23}$ & {$[0.382,0.395]$} & {$[0.316,0.329]$} \\
$\mathrm{fe}_{31}$ & {$[0.039,0.043]$} & {$[0.046,0.050]$} \\
$\mathrm{fe}_{32}$ & {$[107.260,121.019]$} & {$[125.319,139.079]$} \\
$\mathrm{fe}_{33}$ & {$[0.018,0.022]$} & {$[0.018,0.022]$} \\
\hline
\end{tabular}

Analysis results of 2020 and 2025 were obtained using Monte Carlo method, as shown in Table13. It can be seen that $D$ is varied between 0.5 and 0.6 , coordinate development state is barely coordinated, and agricultural water resources utilization lags behind socio-economic development. All the generated results show that agricultural water resources utilization can not catch up with socio-economic development.

Table 13 Average evaluation results of Shanxi in future

\begin{tabular}{ccc}
\hline & 2020 & 2025 \\
\hline $\mathrm{Fa}$ & 0.296 & 0.235 \\
$\mathrm{Fe}$ & 0.522 & 0.478 \\
$T$ & 0.409 & 0.357 \\
$C$ & 0.847 & 0.772 \\
$D$ & 0.588 & 0.524 \\
coordinate development state & $\mathrm{R}$ & $\mathrm{R}$ \\
object of maladjustment & $\mathrm{A}$ & $\mathrm{A}$ \\
\hline
\end{tabular}

Note: R-- barely coordination; A--Agricultural water resources.

Fig. 7 shows distribution statistics of coordinated development degree in 2020 and 2025. The interval of $\mathrm{D}$ is $[0.50,0.66]$, and the average value is 0.588 in 2020 . The interval of $\mathrm{D}$ is $[0.42,0.60]$, and the average value is 0.524 in 2025 . Coordinated development degree has a trend of decreasing markedly, which indicates that agricultural water resources and socio-economic development will be in transitional state. If any effective measure were not applied to balance agricultural water resources and socio-economic development in Shanxi, they might get into maladjustment in the 
foreseeable future. To solve this problem, developing available water resources, popularizing irrigation water saving facilities (Ren and Zhang, 2019) and raising cyclic utilization rate of water are effective countermeasures could be chosen.

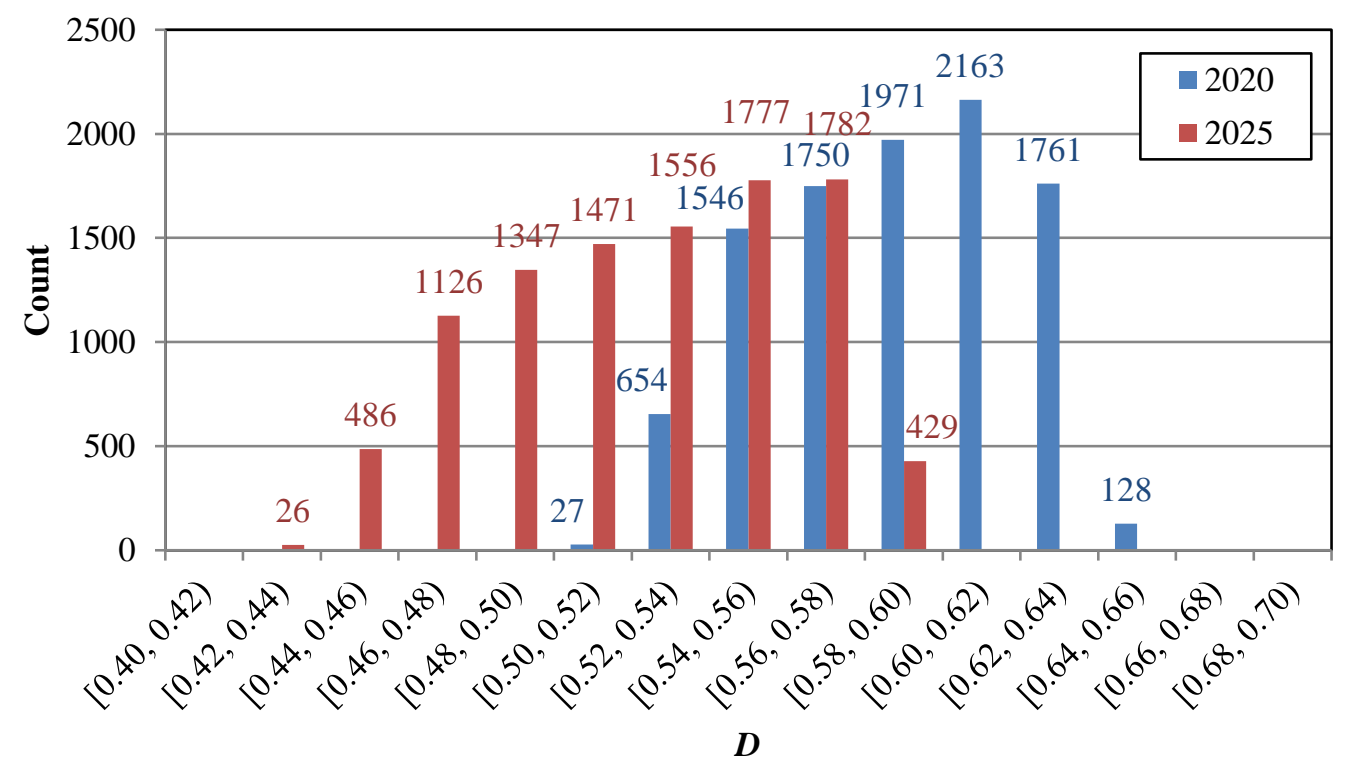

Fig.7 Distribution statistics of coordinated development degree in 2020 and 2025.

\section{Discussion}

The study has proposed a complete evaluation process which pays more attention to uncertain characteristics in the future, instead of simply estimating coordinated development of agricultural water resources and socio-economy. The method provides a referential criterion which includes 9 evaluation indicators of agricultural water resources and 9 evaluation indicators of socio-economic development. To deal with the uncertain problem, Monte Carlo method and fuzzy set method were used in the process. The coordinated development degree, coordinate development state and object of maladjustment can provide decision makers necessary references for 
clarifying the orientation and determining the strategy of development.

\section{Conclusion}

Due to severe shortage of agricultural water resources and unbalanced development of social-economy, conflict between agricultural water resources and socio-economy has become increasingly apparent in the urban development. How to evaluate coordinated development degree of agricultural water resources and socio-economy, considering uncertainty in present status and future, is a challenge.

The study identified 9 evaluation indicators of agricultural water resources and 9 evaluation indicators of socio-economic development as criteria, according to the concept of regional coordinated development. Based on the combined weight of both objective and subjective weight, the comprehensive level, coordination degree and coordinated development degree of agricultural water resources and social-economy development were evaluated. Results show that coordinated development degrees were $(0.7,0.8)$ for most of the cities of Shanxi in 2015. Jincheng had biggest coordinated development degree (0.837), and Yuncheng had smallest one (0.640). To achieve balanced development, it is critical to focus on socio-economic development of Taiyuan and Yanquan, and agricultural water resources utilization of Jinzhong, Yuncheng and Xinzhou. According to the evaluation result of years, the average coordinated development degree is 0.758 , and coordinate development state was intermediate coordinate from 2006 to 2015 . According to the evaluation result of the future, coordinated development degrees are varied between 0.5 and 0.6 , coordinate 
development state is barely coordinated, and agricultural water resources utilization lags behind socio-economic development. Coordinated development degree has a trend of decreasing markedly, which indicates that agricultural water resources and socio-economic development will be in transitional state. To avoid maladjustment, some measures, such as developing available water resources, popularizing irrigation water saving facilities and raising cyclic utilization rate of water should be taken.

The improved method is applicable and can be recommended for evaluation of coordinated development of agricultural water resources and socio-economy. For its applications to other regions, the criteria can be easily modified according to local actuality. The study attempted to evaluate coordinated development degree under uncertainty. However, more uncertainties exist in agricultural water resources and socio-economy development, which make the situation more complex. How to deal with more complex uncertainty and enhance the applicability of the method deserves further study.

\section{Acknowledgements}

This research was supported by the National Natural Science Foundation of China $(51709195,41807130)$, the Youth Science and Technology Research Fund of Shanxi Province (201701D221222), and the Taiyuan University of Science and Technology Scientific Research Initial Funding (20172012, 20182040). 


\section{References}

1. Bao, $\mathrm{C}, \mathrm{He}, \mathrm{DM}$. The causal relationship between urbanization, economic growth and water use change in provincial china. Sustainability. 2015; 7 (12): 16076-16085.

2. Debnath, A, Majumder, M, Pal, M. A Cognitive Approach in Selection of Source for Water Treatment Plant based on Climatic Impact. Water Resources Management. 2015; 29 (6): 1907-1919.

3. Fang, SB, Jia, RF, Tu, WR, Sun, ZL. Assessing factors driving the change of irrigation Water-Use efficiency in china based on geographical features. Water. 2017; 9 (10).

4. Gu, A, Zhang, Y, Pan, BL. Relationship between Industrial Water Use and Economic Growth in China: Insights from an Environmental Kuznets Curve. Water. 2017; 9 (8).

5. Li, M, Fu, Q, Singh, VP, Ji, Y, Liu, D, Zhang, CL, Li, TX. An optimal modelling approach for managing agricultural water-energy-food nexus under uncertainty. Science of the Total Environment. 2019; 651 (1): 1416-1434.

6. Li, M, Fu, Q, Singh, VP, Liu, D, Li, T. Stochastic multi-objective modeling for optimization of water-food-energy nexus of irrigated agriculture. Advances in Water Resources. 2019; 127 : 209-224.

7. Liu, Y, Zhang, F, Zhang, Y. Appraisal of typical rural development models during rapid urbanization in the eastern coastal region of China. Journal of Geographical Sciences. 2009; 19 (5): 557-567.

8. Lu, HW, Huang, GH, He, L. Simulation-Based inexact Rough-Interval programming for 
agricultural irrigation management: A case study in the yongxin county, china. Water Resources Management. 2012; 26 (14): 4163-4182.

9. Ren, C, Zhang, H. An inexact optimization model for crop area under multiple uncertainties. International Journal of Environmental Research and Public Health. 2019; 16.

10. Ren, CF, Li, ZH, Zhang, HB. Integrated multi-objective stochastic fuzzy programming and AHP method for agricultural water and land optimization allocation under multiple uncertainties. Joornal of Cleaner Production. 2019; 210: 12-24.

11. Saaty, TL. The analytic hierarchy process: Planning, priority setting and resource allocation. 1980; McGraw-Hill, New York.

12. Sahoo, M, Sahoo, S, Dhar, A, Pradhan, B. Effectiveness evaluation of objective and subjective weighting methods for aquifer vulnerability assessment in urban context. Journal of Hydrology. 2016; 541: 1303-1315

13. Song, JX, Tang, B, Zhang, JL, Dou, XY, Liu, Q, Shen, WB. System dynamics simulation for optimal stream flow regulations under consideration of coordinated development of ecology and socio-economy in the Weihe River Basin, China. Ecological Engineering. 2018; 124: 51-68.

14. Susnik, J, Molina, J, Vamvakeridou-Lyroudia, LS, Savic, DA, Kapelan, Z. Comparative analysis of system dynamics and Object-Oriented bayesian networks modelling for water systems management. Water Resources Management. 2013; 27 (3): 819-841.

15. Tang, BJ, Hu, YJ, Li, HN, Yang, DW, Liu, JP. Research on comprehensive carrying capacity of Beijing-Tianjin-Hebei region based on state-space method. Natural Hazards. 2016; 841: S113-S128. 
16. Wang, XS, Li, XN, Wang, JW. Urban water conservation evaluation based on multi-grade uncertain comprehensive evaluation method. Water Resources Management. 2018; 32 (2): 417-431.

17. Xiong, Y, Li, JZ, Jiang, DL. Optimization research on supply and demand system for water resources in the Chang-Zhu-Tan urban agglomeration. Journal of Geographical Sciences. 2015; 25 (11): 1357-1376.

18. Yang, G, Guo, P, Huo, L, Ren, C. Optimization of the irrigation water resources for Shijin irrigation district in north China. Agricultural Water Management. 2015; 158: 82-98.

19. Yang, G, Liu, L, Guo, P, Li, M. A flexible decision support system for irrigation scheduling in an irrigation district in China. Agricultural Water Management. 2017; 179: 378-389.

20. Yang, Q, He, L, Liu, XX, Pan, AE. Water resources management in China based on coordinated development index. Desalination and Water Treatment. 2018; 121: 256-264.

21. Yao, JP, Ren, YT, Wei, S, Pei, W. Assessing the complex adaptability of regional water security systems based on a unified co-evolutionary model. Journal of Hydroinformatics. 2018; 20 (1): 34-48.

22. Yuan, Y, Jin, M, Ren, J, Hu, M, Ren, P. The dynamic coordinated development of a regional environment-tourism-economy system: A case study from western Hunan Province, China. Sustainability. 2014; 6 (8): 5231-5251.

23. Yue, Q, Zhang, F, Guo, P. Optimization-Based agricultural Water-Saving potential analysis in minqin county, gansu province china. Water. 2018; 10 (9). 